\title{
Hydro-Ionothermal Synthesis of Lanthanide-Organic Frameworks with 1,4-Phenylenebis(methylene)diphosphonate
}

\author{
Fa-Nian Shi, Tito Trindade, João Rocha,* and Filipe A. Almeida Paz* \\ University of Aveiro, CICECO, Department of Chemistry, Campus Universitário de Santiago, \\ 3810-193 Aveiro, Portugal
}

Received June 17, 2008; Revised Manuscript Received August 26, 2008

\begin{abstract}
A synthetic approach combining hydrothermal and ionothermal (eutectic mixture of choline chloride and malonic acid) procedures is proposed that allowed the isolation of the first lanthanide-organic frameworks with residues of 1,4-phenylenebis(methylene)diphosphonic acid $\left(\mathrm{H}_{4} \mathrm{pmd}\right)$, [ $\left.\mathrm{Ln}(\mathrm{Hpmd})\left(\mathrm{H}_{2} \mathrm{O}\right)\right]$ (where $\mathrm{Ln}^{3+}=\mathrm{Ce}^{3+}$ and $\mathrm{Pr}^{3+}$ ), exhibiting an unprecedented trinodal topology with 3- and 8 -connected nodes. The structural details were unveiled from single-crystal X-ray diffraction and the materials were characterized using standard techniques.
\end{abstract}

Metal-organic frameworks (MOFs) are an attractive class of materials that has received a considerable amount of worldwide attention over the last two decades. ${ }^{1}$ This surge has been primarily motivated by their intriguing structural architectures ${ }^{2}$ and, more recently, from their potential applications. ${ }^{3}$ Remarkably, the most widely employed synthetic strategy is the solvo(hydro)thermal method inherited from zeolite chemistry. More recently, ionothermal synthesis has been used with great success to isolate novel MOFs or coordination complexes, ${ }^{4-6}$ zeolites $^{7}$ and nanomaterials. ${ }^{8}$ Depending on the choice of ionic liquids (ILs) different materials can be isolated and, to date, 1-ethyl-3-methyl imidazolium bromide (EMIm-Br) is the most commonly employed IL solvent and structure-directing agent (SDA). ${ }^{4}$ However, the corresponding cation is usually included in the final product to balance the crystal charge and its removal usually implies a destruction of the framework. Following our interest in the synthesis and structural characterization of MOFs, ${ }^{9}$ in particular those with lanthanides, here we wish to describe a simple and effective method that combines hydrothermal and ionothermal synthetic concepts (hydro-ionothermal synthesis, $\mathrm{HI})$ : eutectic mixtures of choline chloride and malonic acid (CM, melting point $\left.10^{\circ} \mathrm{C}\right)^{10}$ having a small amount of intentionally added distilled water were used as the solvent media in the reaction of lanthanide ions with a bisphosphonic acid source. CM mixtures have been profitably used in the preparation of a number of $d$-block oxalophosphates and oxalo-phosphonates, ${ }^{6}$ but their use with lanthanides and flexible chelating ligands is unknown to date.

The reaction between tetraethyl- $p$-xylylenebisphos-phonate (texbp) and $\mathrm{LnCl}_{3} \cdot 6 \mathrm{H}_{2} \mathrm{O}\left(\mathrm{Ln}^{3+}=\mathrm{Ce}^{3+}\right.$ and $\left.\mathrm{Pr}^{3+}\right)$ in preprepared homogeneous eutectic mixtures of $\mathrm{CM},{ }^{11}$ led to the isolation of phase-pure crystalline materials which were formulated as $\left[\mathrm{Ln}(\mathrm{Hpmd})\left(\mathrm{H}_{2} \mathrm{O}\right)\right]$ (where $\mathrm{Ln}^{3+}=\mathrm{Ce}^{3+}$ for $\mathbf{1}$ and $\mathrm{Pr}^{3+}$ for $\mathbf{2}$; $\mathrm{H}_{4}$ pmd $=1,4$-phenylenebis(methylene)diphosphonic acid, see Scheme 1) on the basis of single-crystal X-ray diffraction studies ${ }^{12}$ and CHN elemental composition studies in combination with EDS data. Even though a handful of frameworks with $d$ - and $p$-block elements and $\mathrm{H}_{4-x} \mathrm{pbp}^{-x}$ residues have been reported, ${ }^{13-16}$ the compounds described here constitute the first examples of framework materials with this ligand coordinated to lanthanide centers. The bulk materials are highly crystalline even though an almost absence of isolated single crystals is clearly notorious (see SEM images in the Supporting Information). Small fragments (cut manually under the microscope) were selected for X-ray structural analysis but, noteworthy, these still diffracted weakly at high angles. Diagnostic vibrational spectroscopy bands (FT-IR and FT-Raman, see the Supporting Information $)^{15,16}$ and powder X-ray diffraction data (data not shown) fully supported the presence of two

* To whom correspondence should be addressed. E-mail: rocha@ua.pt (J.R.); filipe.paz@ua.pt (F.A.A.P.). Fax: (351) 234370084.

\section{Scheme 1. 1,4-Phenylenebis(methylene)diphosphonic Acid}

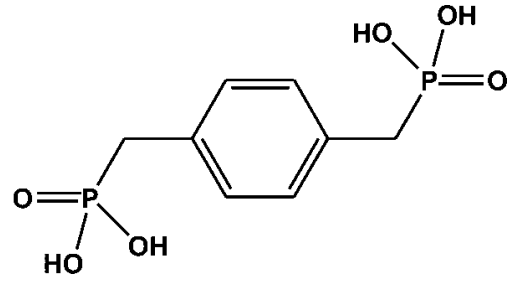

isotructural materials. It is important to emphasize that despite the HI approach was highly reproducible conventional hydrothermal or ionothermal methods failed to produce the desired frameworks (1 and 2).

The in situ generation of $\mathrm{H}_{4}$ pmd (Scheme 1) during the HI synthesis was also unequivocally confirmed by the direct isolation of this organic molecule from the slow evaporation of the autoclave mother liquors from different batches. It is feasible to assume that the addition of a small amount of distilled water to the reactive mixtures promotes hydrolysis of the ester groups of tepbp, thus producing the diphosphonic acid precursor. The crystal structure of this organic molecule, unknown to date, ${ }^{17}$ was determined in the monoclinic $P 2_{1} / n$ space group. ${ }^{18}$ Structural details, including the extended hydrogen bonding network involving the phosphonic acid groups, are provided as Supporting Information.

$\mathbf{1}$ and $\mathbf{2}$ contain a single crystallographically independent $\mathrm{Ln}^{3+}$ center coordinated to one water molecule and to five $\mathrm{O}$-atoms from phosphonate groups in a seven-coordination environment, $\left\{\mathrm{LnO}_{7}\right\}$ (Figure 1). If the $O, O$-chelated $\mathrm{P} 2$ phosphonate group is counted as a single coordination site (bite angles of 56.1(3) and 56.7(2) ${ }^{\circ}$ ), the coordination polyhedron can ultimately be envisaged as a highly distorted octahedron with the cis and trans angles being in the ranges $80.2-109.6^{\circ}$ and $156.6-172.0^{\circ}$ (for 1) and $80.4-107.5^{\circ}$ and $157.2-172.4^{\circ}$ (for 2 ), respectively. We note that this type of $O, O$ chelation is relatively common among crystalline phosphonate-based complexes or materials with various metallic centers which include alkali and alkaline earth elements, transition metals and also a handful of rare-earth cations. ${ }^{17}$ This phosphonate group further establishes a bridge with a neighboring $\mathrm{Ln}^{3+}$ cation leading to the formation of centrosymmetric dimers as depicted in Figure 2 (bottom right). The intradimeric $\operatorname{Ln} 1 \cdots \operatorname{Ln} 1^{\text {iii }}$ distances are of 4.1365(17) and 4.1194(12) $\AA$ for $\mathbf{1}$ and 2, respectively [symmetry code: (iii) $2--x,-y,-z]$. Structural robustness within this dimeric unit is further ensured by the presence of strong and highly directed $\mathrm{O}-\mathrm{H} \cdots \mathrm{O}$ hydrogen bonds involving the coordinated water molecules and the protonated P1 phosphonate groups (see Figure 2 , bottom right). Units are interconnected in the $a b$ plane of the unit cell leading to the formation of a purely inorganic lanthanide 


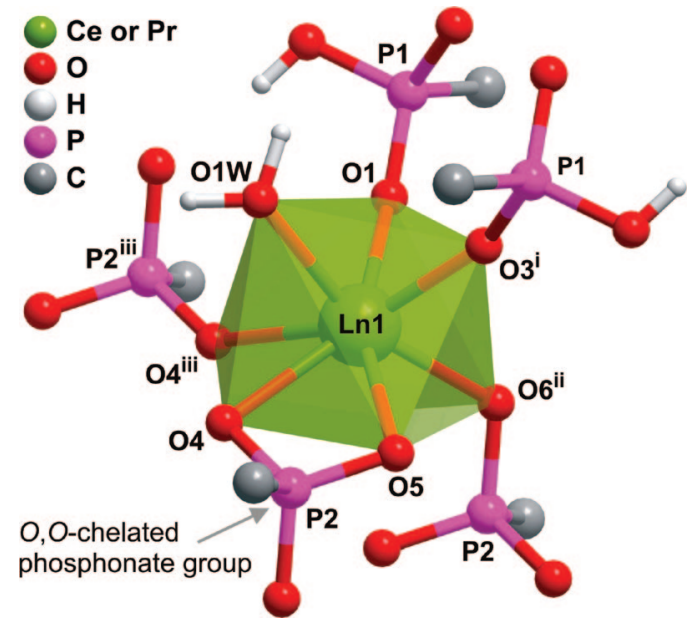

Figure 1. Polyhedral representation of the coordination environment of the $\mathrm{Ln}^{3+}$ centers present in $\left[\mathrm{Ln}(\mathrm{Hpmd})\left(\mathrm{H}_{2} \mathrm{O}\right)\right]$ (where $\mathrm{Ln}^{3+}=\mathrm{Ce}^{3+}$ for 1 and $\mathrm{Pr}^{3+}$ for 2). Selected bond lengths (in $\AA$ ) for 1/2: Ln1-O1 2.362(10)/2.340(8); Ln1-O3 ${ }^{\mathrm{i}} 2.321(12) / 2.307(8) ; \mathrm{Ln} 1-\mathrm{O} 42.567(10) /$ 2.561(7); Ln1-O $4^{\mathrm{iii}} 2.488(11) / 2.462(8) ; \mathrm{Ln} 1-\mathrm{O} 5$ 2.615(11)/2.578(8); Ln1-O6 $6^{\text {ii }} 2.419(10) / 2.403(8)$. A listing of the bond angles is provided as Supporting Information. Symmetry transformations used to generate equivalent atoms: (i) $2-x, 1-y,-z$; (ii) $3-x,-y,-z$; (iii) $2-x$, $-y,-z$.

hydrogenophosphonate layer (Figure 2, top right). Within this inorganic layer, the closest distances between dimeric units are that of the length of the $a$ - and $b$-axes. Connections between adjacent layers are ensured by the $\mathrm{Hpmd}^{3-}$ organic pillars leading to an alternation along the $c$-axis of organic and inorganic fragments as depicted in Figure 2.

Taking as network nodes the phosphorus atoms (two crystallographically independent) and the center of gravity of the afore-

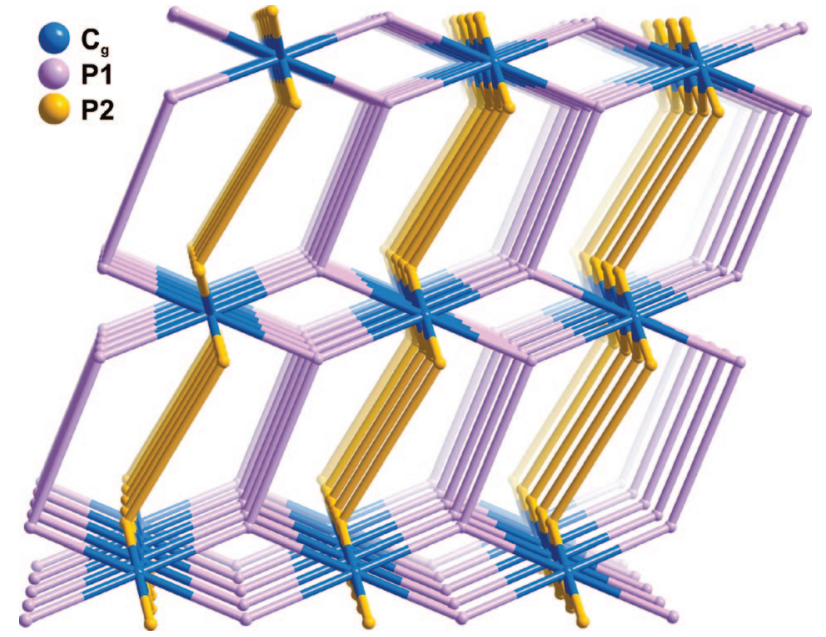

Figure 3. Topological representation of the trinodal frameworks of [ $\left.\mathrm{Ln}(\mathrm{Hpmd})\left(\mathrm{H}_{2} \mathrm{O}\right)\right]: \mathrm{P} 1$ and $\mathrm{P} 2$ correspond to 3-connected nodes and the center of gravity $\left(\mathrm{C}_{\mathrm{g}}\right)$ of the lanthanide dimeric units are 8 -connected nodes. Internodal distances: P1 $\rightarrow$ P1 $7.90 \AA$; P2 $\rightarrow$ P2 $8.44 \AA$ A P1 $\rightarrow$ $\mathrm{C}_{\mathrm{g}} 5.01$ and $5.54 \AA$; $\mathrm{P} 2 \rightarrow \mathrm{C}_{\mathrm{g}} 2.81$ and $4.26 \AA$.

mentioned dimeric unit, $\mathbf{1}$ and $\mathbf{2}$ can be envisaged as trinodal frameworks built-up from two types of 3- (P-atoms) and one type of 8-connected (dimeric unit) nodes with a total Schläfli symbol of $\left\{4.6^{2}\right\} 4\left\{4^{4} \cdot 6^{8} \cdot 8^{16}\right\}$ (Figure 3). To the best of our knowledge, this topology is new. ${ }^{19}$

Thermogravimetric studies unveiled an unusual thermal stability for $\mathbf{1}$ and $\mathbf{2}$ among the MOF family. Indeed, coordinated water molecules and most likely a partial dehydration of the coordinated $\mathrm{Hpbp}^{3-}$ ligand occurs only after ca. $270{ }^{\circ} \mathrm{C}$ (see the Supporting Information). Up to $700{ }^{\circ} \mathrm{C}$ further weight losses are relatively negligible, which is a strong indication that the pillaring organic

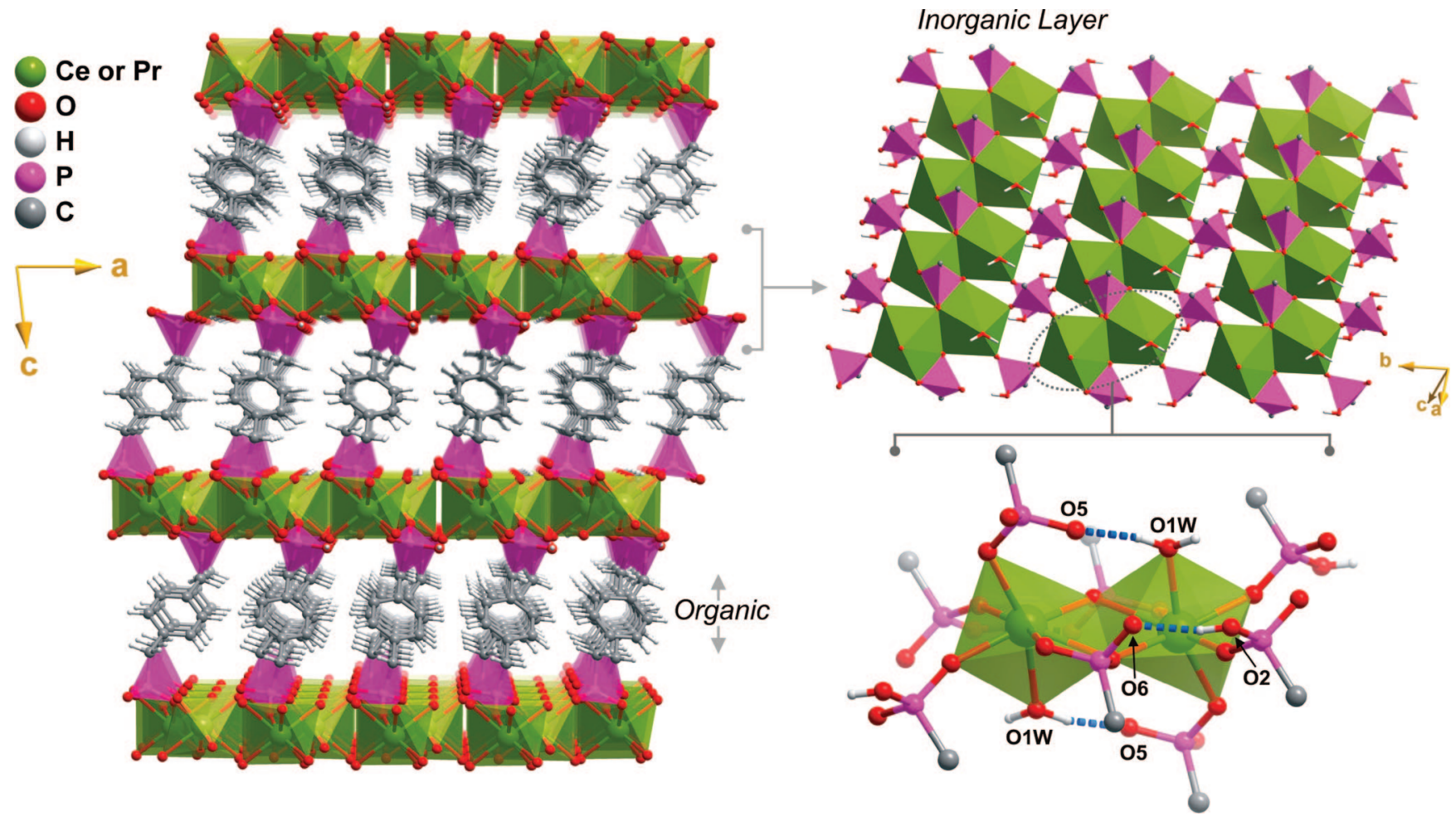

Figure 2. Mixed ball-and-stick and polyhedral representation of the crystal structure of $\left[\mathrm{Ln}(\mathrm{Hpmd})\left(\mathrm{H}_{2} \mathrm{O}\right)\right]\left(\right.$ where $^{\mathrm{Ln}^{3+}}=\mathrm{Ce}^{3+}$ for $\mathbf{1}$ and $\mathrm{Pr}^{3+}$ for 2) emphasizing the alternation along the [001] direction of inorganic lanthanide hydrogenophosphonate layers with organic moieties. $\mathrm{O}-\mathrm{H} \cdots \mathrm{O}$ hydrogen bonds within the centrosymmetric dimeric units are represented as blue-dashed lines. Hydrogen bonding geometry (for $\mathbf{1} / 2$ ): $\mathrm{O} 1 \mathrm{~W}-\mathrm{H} 1 \mathrm{~B} \cdot \cdots \mathrm{O} 5$ $d(\mathrm{D} \cdots \mathrm{A})=2.889(16) / 2.776(11) \AA$ and $\angle(\mathrm{DHA})=150 / 168^{\circ} ; \mathrm{O} 2-\mathrm{H} 2 \cdots \mathrm{O} 6 d(\mathrm{D} \cdots \mathrm{A})=2.672(16) / 2.664(12) \AA$ and $\angle(\mathrm{DHA})=158 / 169^{\circ}$. Symmetry codes associated with equivalent atoms have been omitted for clarity. 
residues remain intact within the framework. This behavior is in line with that described for similar materials, in particular with those reported by Zhu and Qiu and collaborators (a layered $\mathrm{Co}^{2+}$ material which exhibits reversible dehydration properties) ${ }^{13}$ and Stock and co-workers. ${ }^{15}$ Further studies on the detailed decomposition pathway of these compounds are in progress.

In conclusion, a new "hybrid" approach combining hydrothermal and ionothermal strategies (based on eutectic 1:1 mixtures of choline chloride and malonic acid) has been presented which allowed the isolation of the first lanthanide-organic frameworks having residues of 1,4-phenylenebis(methylene)diphosphonic acid, exhibiting a new trinodal structural topology and high thermal stability. The present work may open new perspectives in this field of research based on the simple idea of combining distinct synthetic strategies to direct the self-assembly of new multidimensional materials with intriguing architectures. At present, we are developing the strategies here described with other lanthanide ions with the final objective to isolate photoluminescent materials.

Acknowledgment. We thank FEDER, POCI (Portugal), and Fundação para a Ciência e a Tecnologia (FCT, Portugal) for their financial support (POCI-PPCDT/QUI/58377/2004), for funding toward the purchase of the single-crystal diffractometer, and for postdoctoral research Grant SFRH/BPD/9309/2002 (to F.-N.S.).

Supporting Information Available: Crystallographic information files (CIF) for compounds 1-3. Additional experimental details and structural characterization data (SEM, FT-IR and FT-Raman, TG and structural drawing of $\mathbf{3}$ ) (PDF). This material is available free of charge via the Internet at http://pubs.acs.org.

\section{References}

(1) Champness, N. R. Making Coordination Frameworks. In Making Crystals by Design-Methods, Techniques and Applications, 1st ed.; Braga, D., Grepioni, F., Eds.; Wiley-VCH Verlag GmbH \& Co. KGaA: Weinheim, Germany, 2007; pp 193-208.

(2) Carlucci, L.; Ciani, G.; Proserpio, D. M. Coord. Chem. Rev. 2003, 246, 247-289.

(3) (a) Kitagawa, S.; Kitaura, R.; Noro, S. Angew Chem., Int. Ed. 2004, 43, 2334-2375. (b) Kitagawa, S.; Uemura, K. Chem. Soc. Rev. 2005, 34, 109-119.

(4) Parnham, E. R.; Morris, R. E. Acc. Chem. Res. 2007, 40, 1005-1013. Lin, Z. J.; Wragg, D. S.; Warren, J. E.; Morris, R. E. J. Am. Chem. Soc. 2007, 129, 10334-10335. Lin, Z. J.; Slawin, A. M. Z.; Morris, R. E. J. Am. Chem. Soc. 2007, 129, 4880-4881.

(5) Liao, J. H.; Huang, W. C. Inorg. Chem. Commun. 2006, 9, 12271231. Hogben, T.; Douthwaite, R. E.; Gillie, L. J.; Whitwood, A. C. CrystEngComm 2006, 8, 866-868. Lin, Z. J.; Wragg, D. S.; Morris, R. E. Chem. Commun. 2006, 2021-2023.

(6) Tsao, C. P.; Sheu, C. Y.; Nguyen, N.; Lii, K. H. Inorg. Chem. 2006, 45, 6361-6364. Sheu, C. Y.; Lee, S. F.; Lii, K. H. Inorg. Chem. 2006, 45, 1891-1893.

(7) Parnham, E. R.; Morris, R. E. Chem. Mater. 2006, 18, 4882-4887. Parnham, E. R.; Drylie, E. A.; Wheatley, P. S.; Slawin, A. M. Z.; Morris, R. E. Angew Chem., Int. Ed. 2006, 45, 4962-4966. Xu, Y. P.; Tian, Z. J.; Wang, S. J.; Hu, Y.; Wang, L.; Wang, B. C.; Ma, Y. C.; Hou, L.; Yu, J. Y.; Lin, L. W. Angew. Chem., Int. Ed. 2006, 45, 39653970. Wang, L.; Xu, Y. P.; Wei, Y.; Duan, J. C.; Chen, A. B.; Wang, B. C.; Ma, H. J.; Tian, Z. J.; Lin, L. W. J. Am. Chem. Soc. 2006, 128 , 7432-7433. Parnham, E. R.; Morris, R. E. J. Am. Chem. Soc. 2006, 128, 2204-2205. Xu, Y. P.; Tian, Z. J.; Xu, Z. S.; Wang, B. C.; Li, P.; Wang, S. J.; Hu, Y.; Ma, Y. C.; Li, K. L.; Liu, Y. J.; Yu, J. Y.; Lin, L. W. Chin. J. Catal. 2005, 26, 446-448. Cooper, E. R.; Andrews, C. D.; Wheatley, P. S.; Webb, P. B.; Wormald, P.; Morris, R. E. Nature 2004, 430, 1012-1016.

(8) Biswas, K.; Rao, C. N. R. Chem.-Eur. J. 2007, 13, 6123-6129. Zhu, H. G.; Huang, J. F.; Pan, Z. W.; Dai, S. Chem. Mater. 2006, 18, 44734477.

(9) Harbuzaru, B. V.; Corma, A.; Rey, F.; Atienzar, P.; Jorda, J. L.; Garcia, H.; Ananias, D.; Carlos, L. D.; Rocha, J. Angew Chem., Int. Ed. 2008, 47, 1080-1083. Chelebaeva, E.; Larionova, J.; Guari, Y.; Ferreira, R. A. S.; Carlos, L. D.; Paz, F. A. A.; Trifonov, A.; Guerin, C. Inorg. Chem. 2008, 47, 775-777. Soares-Santos, P. C. R.; Cunha-Silva, L.; Paz, F. A. A.; Sá Ferreira, R. A.; Rocha, J.; Trindade, T.; Carlos,
L. D.; Nogueira, H. I. S. Cryst. Growth Des. 2008, 2505-2516. Shi, F. N.; Cunha-Silva, L.; Ferreira, R. A. S.; Mafra, L.; Trindade, T.; Carlos, L. D.; Paz, F. A. A.; Rocha, J. J. Am. Chem. Soc. 2008, 130, 150-167. Shi, F. N.; Cunha-Silva, L.; Trindade, T.; Paz, F. A. A.; Rocha, J. Cryst. Growth Des. 2008, n/a> Liu, F. Y.; Roces, L.; Ferreira, R. A. S.; Garcia-Granda, S.; Garcia, J. R.; Carlos, L. D.; Rocha, J. J. Mater. Chem. 2007, 17, 3696-3701. Cunha-Silva, L.; Mafra, L.; Ananias, D.; Carlos, L. D.; Rocha, J.; Paz, F. A. A. Chem. Mater. 2007, 19, 3527-3538. Paz, F. A. A.; Klinowski, J. Pure Appl. Chem. 2007, 79, 1097-1110. Paz, F. A. A.; Rocha, J.; Klinowski, J.; Trindade, T.; Shi, F. N.; Mafra, L. Prog. Solid State Chem. 2005, 33, 113-125.

(10) Abbott, A. P.; Boothby, D.; Capper, G.; Davies, D. L.; Rasheed, R. K. J. Am. Chem. Soc. 2004, 126, 9142-9147.

(11) Starting chemicals were readily available from commercial sources and were used as received without further purification: choline chloride $\left(\mathrm{C}_{5} \mathrm{H}_{14} \mathrm{ONCl}, \geq 98 \%\right.$, Aldrich), malonic acid $\left(\mathrm{C}_{3} \mathrm{H}_{4} \mathrm{O}_{4}, 99 \%\right.$, Aldrich), tetraethyl- $p$-xylylenebisphosphonate (texbp, $\mathrm{C}_{16} \mathrm{H}_{28} \mathrm{O}_{6} \mathrm{P}_{2}, \geq 98 \%$, Epsilon Chimie) and lanthanide(III) chloride hydrates $\left(\mathrm{CeCl}_{3} \cdot 6 \mathrm{H}_{2} \mathrm{O}\right.$ and $\mathrm{PrCl}_{3} \cdot 6 \mathrm{H}_{2} \mathrm{O}, \geq 99.9 \%$ Aldrich). Synthesis of 1: an eutectic mixture (ionic liquid) was made by heating choline chloride and malonic acid in a ca. 1: 1 mole ratio at about $80^{\circ} \mathrm{C}$ with magnetic stirring until a homogeneous transparent colorless liquid was formed (CM); $0.22 \mathrm{~g}$ of texbp, $0.11 \mathrm{~g}$ of $\mathrm{CeCl}_{3} \cdot 6 \mathrm{H}_{2} \mathrm{O}$, and $1.0 \mathrm{~g}$ of distilled water were added into ca. $3.0 \mathrm{~g}$ of CM. The resulting mixture was stirred for $1 \mathrm{~h}$ until a homogeneous viscous gel was formed. This gel was transferred into $45 \mathrm{~mL}$ Teflon-lined stainless steel reaction vessels (Parr Instruments) which were sealed and heated at $120^{\circ} \mathrm{C}$ for $80 \mathrm{~h}$. The obtained solid products were constituted by a mixture of white single-crystalline particles and a white powder which were readily separated by ultrasonication with copious amounts of ethanol (ca. $50 \mathrm{~mL}$ ) followed by distilled water (ca. $100 \mathrm{~mL}$ ). Crystalline material was dried at ambient temperature. Yield of ca. 64\%. Elemental composition (theoretical values inside the parentheses): C, 23.45\% (22.81\%); $\mathrm{H}$, $2.98 \%(2.63 \%)$. Synthesis of 2: this material was obtained using a similar experimental procedure to that of $\mathbf{1}$ but using instead $0.22 \mathrm{~g}$ of texbp, $0.30 \mathrm{~g}$ of $\mathrm{PrCl}_{3} \cdot 6 \mathrm{H}_{2} \mathrm{O}$, and $1.8 \mathrm{~g}$ of distilled water. Yield of ca. 53\%. Elemental composition (theoretical values inside the parentheses): C, $23.40 \%$ (22.77\%); H, 2.92\% (2.63\%).

(12) Single-crystal X-ray structure analysis: single crystals were mounted on Hampton Research CryoLoops using FOMBLIN Y perfluoropolyether vacuum oil (LVAC 25/6) purchased from Aldrich with the help of a Stemi 2000 stereomicroscope equipped with Carl Zeiss lenses. Data were collected on a Bruker X8 Kappa APEX II charge-coupled device $(\mathrm{CCD})$ area-detector diffractometer (Mo $\mathrm{K}_{\alpha}$ graphite-monochromated radiation, $\lambda=0.71073 \AA$ ) controlled by the APEX-2 software package (version 2.1-RC13; 2006), and equipped with an Oxford Cryosystems Series 700 cryostream. Images were processed using the software package SAINT+ (version 7.23a; 1997-2005), and data were corrected for absorption by the multi-scan semi-empirical method implemented in SADABS (version 2.01; 1998). The structures were solved using the Patterson synthesis algorithm implemented in SHELXS-97, which allowed the immediate location of the $\mathrm{Ln}^{3+}$ metallic centres. All remaining non-hydrogen atoms were located from difference Fourier maps calculated from successive full-matrix least squares refinement cycles on $\mathrm{F}^{2}$ using SHELXL-97. All non-hydrogen atoms were successfully refined using anisotropic displacement parameters. Crystal Data for $1: \mathrm{C}_{8} \mathrm{H}_{11} \mathrm{CeO}_{7} \mathrm{P}_{2}, M=421.23$, triclinic, space group $P \overline{1}, Z=2, a=5.7048(6) \AA, b=9.5728(9) \AA, c=$ 11.6025(13) $\AA, \alpha=73.808(5)^{\circ}, \beta=80.120(5)^{\circ}, \gamma=78.725(5)^{\circ}, V$ $=592.12(11) \AA^{3}, \mu\left(\mathrm{Mo}_{\mathrm{K} \alpha}\right)=4.136 \mathrm{~mm}^{-1}, D_{\mathrm{c}}=2.363 \mathrm{~g} \mathrm{~cm}^{-3}$, colorless plates with crystal size of $0.10 \times 0.03 \times 0.01 \mathrm{~mm}^{3}$. Independent reflections $2124\left(R_{\text {int }}=0.0608\right)$. Final $R_{1}=0.0729[I>$ $2 \sigma(I)]$ and $w R_{2}=0.1887$ (all data). Data completeness to theta $=$ $25.34^{\circ}, 98.2 \%$. CCDC 691170. Crystal Data for 2: $\mathrm{C}_{8} \mathrm{H}_{11} \mathrm{O}_{7} \mathrm{P}_{2} \mathrm{Pr}, M$ $=422.02$, triclinic, space group $P \overline{1}, Z=2, a=5.6753(3) \AA, b=$ 9.5280(4) $\AA, c=11.5759(5) \AA, \alpha=73.985(2)^{\circ}, \beta=80.573(3)^{\circ}, \gamma$ $=79.193(2)^{\circ}, V=586.82(5) \AA^{3}, \mu\left(\mathrm{Mo}_{\mathrm{K} \alpha}\right)=4.446 \mathrm{~mm}^{-1}, D_{\mathrm{c}}=2.388$ $\mathrm{g} \mathrm{cm}^{-3}$, colorless plates with crystal size of $0.12 \times 0.06 \times 0.02 \mathrm{~mm}^{3}$. Independent reflections $2078\left(R_{\text {int }}=0.0334\right)$. Final $R_{1}=0.0487[I>$ $2 \sigma(I)]$ and $w R_{2}=0.1310$ (all data). Data completeness to theta $=$ $25.34^{\circ}, 96.5 \%$. CCDC 691171.

(13) Li, H.; Zhu, G. S.; Guo, X. D.; Sun, F. X.; Ren, H.; Chen, Y.; Qiu, S. L. Eur. J. Inorg. Chem. 2006, 412, 3-4128.

(14) Harvey, H. G.; Herve, A. C.; Hailes, H. C.; Attfield, M. P. Chem. Mater. 2004, 16, 3756-3766. Belier, F.; Riou-Cavellec, M.; Vichard, D.; Riou, D. C. R. Acad. Sci., Ser. II C 2000, 3, 655-660. Konar, S.; Zon, J.; Prosvirin, A. V.; Dunbar, K. R.; Clearfield, A. Inorg. Chem. 2007, 46, 5229-5236. 
(15) Irran, E.; Bein, T.; Stock, N. J. Solid State Chem. 2003, 173, 293298.

(16) Stock, N.; Guillou, N.; Bein, T.; Ferey, G. Solid State Sci. 2003, 5, 629-634. Stock, N.; Bein, T. J. Solid State Chem. 2002, 167, 330336.

(17) Allen, F. H. Acta Crystallogr., Sect. B 2002, 58, 380-388. Allen, F. H.; Motherwell, W. D. S. Acta Crystallogr., Sect. B 2002, 58, 407-422.

(18) Crystal Data for 3: $\mathrm{C}_{8} \mathrm{H}_{12} \mathrm{O}_{6} \mathrm{P}_{2}, M=266.12$, monoclinic, space group $P 2_{1} / n, Z=2, a=8.5172(5) \AA, b=7.7403(4) \AA, c=9.1430(5) \AA$, $\beta=115.980(2)^{\circ}, V=541.85(5) \AA^{3}, \mu\left(\mathrm{MoK}_{\alpha}\right)=0.411 \mathrm{~mm}^{-1}, D_{\mathrm{c}}=$
$1.631 \mathrm{~g} \mathrm{~cm}^{-3}$, colorless blocks with crystal size of $0.28 \times 0.28 \times$ $0.24 \mathrm{~mm}^{3}$. Independent reflections $1461\left(R_{\text {int }}=0.0221\right)$. Final $R_{1}=$ $0.0250[I>2 \sigma(I)]$ and $w R_{2}=0.0752$ (all data). Data completeness to theta $=29.13^{\circ}, 99.8 \%$. CCDC 691172 .

(19) Blatov, V. A.; Shevchenko, A. P. TOPOS, version 4.0 Professional (beta evaluation); Samara State University: Samara, Russia, 2006 Blatov, V. A.; Shevchenko, A. P.; Serezhkin, V. N. J. Appl. Crystallogr. 2000, 33, 1193.

\section{CG800639X}

